\title{
ANALISIS EMPOWERMENT DAN EMOTIONAL CAPITAL PADA STAF PENDIDIK DI FAKULTAS KEPERAWATAN DAN KEBIDANAN UNUSA
}

\author{
Eppy Setiyowati
}

\author{
Fakultas Keperawatan dan Kebidanan \\ Universitas Nahdlatul Ulama Surabaya, Jalan Smea 57 Surabaya \\ Email: eppyseti@gmail.com
}

\begin{abstract}
Development of resources for organizations, especially educational organizations, namely the lecturer is essentially an investment. Educational staff activity trends for 3 years have decreased by $13 \%$, this is one of the problems for a college institution in emotional capital in a lecturer. The purpose of this research is to analyze empowerment and emotional capital in the staff of educator in Unusa. The research design was survey with cross sectional approach. The population is all lecturers in the Faculty of Nursing and Midwifery as many as 73 people, Sample is a permanent lecturer and has had the certificate of teaching as many as 16 people, the sampling is done through simple random sampling. Dependent variable is empowerment and independent variable is emotional capital. The result of this research showed that spearman rank analysis got significance level $p=0,005<\alpha=0,05$ meaning Ho rejected means there is relationship between empowerment with Emotional capital. The conclusion of this study shows that the dimension of emotional capital in the sub variable self awarness has a very important meaning for the management of human resources. It is recommended for organizers of the organization especially in the field of human resources management to give attention to the self awarness of the employees.
\end{abstract}

Keywords: empowerment, emotional capital

\begin{abstract}
Abstrak: Pengembangan sumber daya bagi organisasi khususnya organisasi pendidikan yaitu dosen pada hakekatnya adalah investasi. Tren aktivitas staf pendidik untuk penelitian selama 3 tahun mengalami penurunan sebesar $13 \%$, hal ini merupakan salah satu masalah bagi sebuah institusi perguruan tinggi dalam emotional capital pada diri seorang dosen. Tujuan penelitian melakukan analisis empowerment dan emotional capital pada staf pendidik di Unusa. Desain penelitian adalah survei dengan pendekatan cross sectional. Populasi adalah semua dosen di Fakultas Keperawatan dan Kebidanan sebanyak 73 orang, Sample adalah dosen tetap dan telah memiliki akta mengajar sebanyak 16 orang, sampling dilakukan melalui simple random sampling. Variabel dependen adalah empowerment sedangkan variabel independen adalah emotional capital. Hasil penelitian menunjukan analisis rank spearman didapatkan tingkat signifikansi $\mathrm{p}=0,005<\alpha=0,05$ yang berarti Ho ditolak artinya terdapat hubungan antara empowerment dengan Emotional capital. Kesimpulan penelitian ini menunjukan bahwa dimensi emotional capital pada sub variabel self awarness mempunyai arti yang sangat penting bagi pengelolaan sumber daya manusia. Disarankan bagi pengelola organisasi khususnya bidang managemen sumber daya manusia untuk memberika perhatian pada self awarness para karyawan.
\end{abstract}

Kata Kunci: empowerment, emotional capital 


\section{PENDAHULUAN}

Menelusuri tahun demi tahun di abad 21 ini persaingan di semua sektor semakin ketat. Untuk memenangkannya, setiap organisasi, sektor privat maupun publik, harus memiliki keunggulan kompetitif (competitive advantage) tertentu dibandingkan dengan organisasi lainnya. Keunggulan ini dapat dibentuk melalui berbagai cara, seperti menciptakan produk dengan desain yang unik, penggunaan teknologi modern, desain organisasi, dan yang terpenting adalah manajemen Sumber Daya Manusia (SDM) secara efektif. Produk yang dimaksud disini tentunya tidak hanya berupa barang yang tangible tetapi juga jasa atau layanan yang intangible. Khusus dalam konteks manajemen SDM, pimpinan perlu meningkatkan berbagai potensi SDM agar mampu memberdayakannya secara optimal dalam mencapai kinerja. Sehingga mampu mendudukkan organisasi pada posisi yang lebih baik dibandingkan dengan organisasi lainnya.

Pengembangan SDM bagi organisasi khususnya organisasi pendidikan pada hakekatnya adalah investasi. Investasi dalam pengembangan SDM merupakan pengeluaran yang ditujukan untuk memperbaiki kapasitas produktif dari manusia, melalui upaya peningkatan kesehatan, pendidikan dan pelatihan kerja. Alasan logis yang dapat dikemukakan adalah bahwa staf kerja yang sehat, terdidik, dan terampil akan menjadi angkatan kerja yang produktif, dan selanjutnya peningkatan produktifitas berarti peningkatan returns. Dengan manajemen SDM yang baik, organisasi akan memiliki kekuatan kompetitif dan akan menjadi sulit untuk ditiru, sehingga beberapa sumber keberhasilan kompetitif tradisional seperti teknologi proses produksi, proteksi pasar, akses terhadap sumber keuangan dan skala ekonomi seharusnya menjadi lebih berdaya guna.

Berdasarkan hasil pengamatan yang dilakukan oleh penulis selama 2 tahun pada staf pendidik dan kependidikan di UNUSA (Universitas Nahdatul Ulama Surabaya) dapat di data sebagai berikut;

Tabel 1 Aktivitas Staf Pendidik Pada Prodi DIII Keperawatan UNUSA Selama 3 Tahun

\begin{tabular}{|l|l|c|c|c|c|c|c|}
\hline No & Kegiatan & \multicolumn{6}{|c|}{ Tahun } \\
\hline & & \multicolumn{2}{|c|}{2010} & \multicolumn{2}{c|}{$\mathbf{2 0 1 1}$} & \multicolumn{2}{|c|}{$\mathbf{2 0 1 2}$} \\
\hline & & $\mathbf{N}$ & $\mathbf{\%}$ & $\mathbf{N}$ & $\mathbf{\%}$ & $\mathbf{N}$ & $\mathbf{\%}$ \\
\hline 1. & Pendidikan & 6 & 78 & 3 & 39 & 3 & 39 \\
\hline 2. & Pengajaran & 13 & 100 & 13 & 100 & 13 & 100 \\
\hline 3. & Penelitian & 5 & 65 & 4 & 52 & - & - \\
\hline 4. & Pengmasy & 6 & 78 & 10 & & 13 & 100 \\
\hline 5. & $\begin{array}{l}\text { Civitas } \\
\text { Akademika }\end{array}$ & 3 & 39 & 3 & 39 & 3 & 39 \\
\hline
\end{tabular}

Pada Tabel 1 dapat dipahami bahwa tren aktivitas staf pendidik untuk penelitian selama 3 tahun mengalami penurunan sebesar $13 \%$, hal ini merupakan salah satu masalah bagi sebuah institusi perguruan tinggi dalam melakukan salah satu penilaian terhadap kinerja dosen.

Dengan melihat tren terhadap kinerja penelitian bagi para staf pendidik, maka peneliti berusaha untuk melakukan pendekatan manajerial guna menyelesaikan masalah terhadap aktivitas staf pendidik. Pendekatan manajerial yang dilakukan tersebut mengadop dari teori Cummings \& Worley (2005) dalam sebuah buku yang berjudul Organization Development and Change. Berdasarkan konsep empowerment dengan dimensi partisipasi, dukungan sosial dan persepsi terhadap kemandirian kerja mampu melakukan peningkatan terhadap kinerja melalui emotional capital dengan dimensi self awearness dan social awearness.

Tujuan penelitian adalah melakukan analisis empowerment dan emotional capital pada staf pendidik pada Fakultas Keperawatan dan Kebidanan UNUSA.

\section{METODE}

Desain dalam proposal penelitian ini adalah survei dengan pendekatan cross sectional. Penelitian dilakukan pada 3 
(tiga) program studi yaitu prodi DIII keperawatan, DIII Kebidanan dan S1 Keperawatan di Fakultas Keperawatan dan Kebidanan UNUSA. Pengumpulan data dilakukan melalui penyebaran kuesioner, Koding pada semua kuesioner telah dilakukan selanjutnya entre dan clearing data, data yang tidak sesuai dengan pengukuran yang telah ditetapkan dilakukan klarifikasi dengan kuesioner selanjutnya di analisis melalui rank spearman.

\section{HASIL \& PEMBAHASAN Hasil}

Umur responden merupakan umur dari para partisipan yang mengikuti proses penelitian ini melalui pengisian kuesioner, umur responden yang dimaksud adalah umur ketika para responden melakukan pengisian kuesioner. Secara diskriptif umur responden disajikan pada Tabel berikut,

Tabel 2 Data Umur Responden Pada Staf Pendidik FKK UNUSA Tahun 2014

\begin{tabular}{|c|c|c|c|}
\hline No & Umur Responden & \multicolumn{2}{|c|}{ Frekuensi } \\
\hline & & N & \% \\
\hline 1. & $20-30$ Tahun & 7 & 41 \\
\hline 2. & $31-40$ Tahun & 6 & 35 \\
\hline 3. & $41-50$ Tahun & 4 & 34 \\
\hline & Jumlah & 17 & 100 \\
\hline
\end{tabular}

Pada Tabel 2 dapat diketahui bahwa umur responden pada saat pengisian kuesioner umur 20 - 30 tahun yaitu hampir seluruhnya (41\%). Hal tersebut menunjukan bahwa umur responden masih dalam kategori produktif dan merupakan peluang bagi institusi pendidikan untuk mengembangkan organisasi ke depan terutama dalam memberdayakan dosen sesuai dengan tugas pokok dan fungsinya yaitu Tridharma Perguruan Tinggi.

Tingkat pendidikan merupakan tingkat pendidikan responden ketika melakukan pengisian kuesioner. Tingkat pendidikan meliputi tingkat Diploma 4 (D4), Strata 1 (S1), Strata 2 (S2), Strata 3
(S3). Hasil penelitian berdasarkan tingkat pendidikan sebagaimana ditampilkan pada Tabel 4.2 berikut,

Tabel 3 Tingkat Pendidikan Responden Pada Staf Pendidik FKK UNUSA Tahun 2014

\begin{tabular}{|c|c|c|c|}
\hline No & $\begin{array}{c}\text { Tingkat Pendidikan } \\
\text { Responden }\end{array}$ & \multicolumn{2}{|c|}{ Frek } \\
\hline & & N & $\%$ \\
\hline 1. & D 4 & 2 & 11,7 \\
\hline 2. & S1 & 4 & 23,5 \\
\hline 3. & S2 & 11 & 64,8 \\
\hline & Jumlah & 17 & 100 \\
\hline
\end{tabular}

Pada Tabel 3 dapat diketahui bahwa tingkat pendidikan responden sebagian besar S2 sebesar $64,8 \%$. Hal tersebut menunjukan bahwa tingkat pendidikan responden merupakan peluang bagi institusi untuk memberdayakan kemampuan berkarier sesuai dengan minat yang dimiliki oleh para responden.

Hasil penelitian pada variabel empowerment merupakan kompilasi antara partisipasi, dukungan sosial dan persepsi terhadap empowerment, setiap subvariabel tersebut disajikan pada tabel berikut:

Tabel 4 Distribusi frekuensi partisipasi pada staf pendidik Di FKK Unusa Tahun 2014

\begin{tabular}{|l|l|l|l|}
\hline No & Partisipasi & Frek & \multicolumn{1}{c|}{$\%$} \\
\hline 1 & Rendah & 6 & 35,3 \\
\hline 2 & Sedang & 10 & 58,8 \\
\hline 3 & Tinggi & 1 & 5,9 \\
\hline \multicolumn{2}{|c|}{ Jumlah } & 17 & 100 \\
\hline
\end{tabular}

Pada Tabel 4 dapat diketahui bahwa partisipasi pada staf pendidik di Fakultas Keperawatan dan Kebidanan Unusa sebagian besar $(58,8 \%)$ sedang.

Hasil distribusi frekuensi dukungan sosial pada staf pendidik di Fakultas Keperawatan dan Kebidanan sebagaimana ditampilkan pada tabel berikut:

Tabel 5 Distribusi frekuensi dukungan sosial pada staf pendidik Di Fakultas Keperawatan dan Kebidanan Unusa Tahun 2014

\begin{tabular}{l|c|c|c|} 
No & Dukungan & Frek & $\%$ \\
\hline
\end{tabular}




\begin{tabular}{|l|l|l|l|}
\hline & \multicolumn{1}{|c|}{ sosial } & & \\
\hline 1 & Rendah & 6 & 35,3 \\
\hline 2 & Sedang & 6 & 35,3 \\
\hline 3 & Tinggi & 5 & 29,4 \\
\hline & Jumlah & 17 & 100 \\
\hline
\end{tabular}

Pada Tabel 5 dapat disimpulkan bahwa dukungan sosial pada staf pendidik di Fakultas Keperawatan dan Kebidanan Unusa menunjukan sebagian kecil $(29,3$ $\%)$ tinggi.

Hasil distribusi frekuensi persepsi terhadap empowerment pada staf pendidik di Fakultas Keperawatan dan Kebidanan sebagaimana disajikan pada tabel berikut:

Tabel 6 Distribusi frekuensi persepsi terhadap empowerment pada staf pendidik Di Fakultas Keperawatan dan Kebidanan Unusa Tahun 2014

\begin{tabular}{|l|l|l|l|}
\hline No & $\begin{array}{c}\text { persepsi } \\
\text { terhadap } \\
\text { empowerment }\end{array}$ & Frek & \% \\
\hline 1 & Lemah & 13 & 76,5 \\
\hline 2 & Sedang & 3 & 17,6 \\
\hline 3 & Kuat & 1 & 5,9 \\
\hline \multicolumn{2}{|c|}{ Jumlah } & 17 & 100 \\
\hline
\end{tabular}

Pada Tabel 6 dapat diketahui bahwa persepsi terhadap empowerment pada staf pendidik Di Fakultas Keperawatan dan Kebidanan Unusa sebagian besar $(76,5)$ lemah.

Hasil penelitian emotional capital merupakan kompilasi antara self awarness dan social awarness, distribusi frekuensi self awarness dan social awarness, disajikan pada tabel berikut:

Tabel 7 Distribusi frekuensi self awarness pada staf pendidik Fakultas Keperawatan dan Kebidanan Unusa Tahun 2014

\begin{tabular}{|c|c|c|c|}
\hline No & $\begin{array}{c}\text { Self } \\
\text { awarness }\end{array}$ & Frek & \% \\
\hline 1 & Rendah & 2 & 11,8 \\
\hline 2 & Sedang & 10 & 58,8 \\
\hline 3 & Tinggi & 5 & 29,4 \\
\hline \multicolumn{2}{|c|}{ Jumlah } & 17 & 100 \\
\hline
\end{tabular}

Pada tabel 7 dapat disimpulkan bahwa self awarness pada staf pendidik Fakultas Keperawatan dan Kebidanan Unusa menunjukan bahwa sebagian besar $(58,8 \%)$ sedang.

Tabel 8 Distribusi frekuensi social awarness pada staf pendidik Fakultas Keperawatan dan Kebidanan Unusa Tahun 2014

\begin{tabular}{|c|c|c|c|}
\hline No & $\begin{array}{c}\text { Social } \\
\text { awarness }\end{array}$ & Frek & \% \\
\hline 1 & Rendah & 1 & 5,9 \\
\hline 2 & Sedang & 7 & 41,2 \\
\hline 3 & Tinggi & 9 & 52,9 \\
\hline \multicolumn{2}{|c|}{ Jumlah } & 17 & 100 \\
\hline
\end{tabular}

Tabel 8 menunjukan bahwa social awarness pada staf pendidik pada Fakultas Keperawatan dan Kebidanan Unusa sebagian besar $(52,9 \%)$ tinggi.

Hasil penelitian empowerment merupakan hasil kompilasi antara partisipasi, dukungan sosial dan persepsi terhadap empowerment, sedangkan emotional capital merupakan kompilasi antara self awarness dan social awarness .

Distribusi frekuensi hasil penelitian empowerment sebagaimana ditampilkan pada Tabel 4.9 berikut;

Tabel 9 Distribusi frekuensi empowerment pada staf pendidik UNUSA tahun 2014

\begin{tabular}{|c|c|c|c|}
\hline No & empowerment & Frek & $\%$ \\
\hline 1. & Rendah & 10 & 58,8 \\
\hline 2. & Tinggi & 7 & 41,2 \\
\hline & Total & 17 & 100 \\
\hline
\end{tabular}
disimpulkan bahwa empowerment pada staf pendidik UNUSA sebagian besar $(58,8 \%)$ rendah.

Distribusi frekuensi hasil penelitian emocional capital sebagaimana ditampilkan pada Tabel 4.10 berikut;

Tabel 10 Distribusi frekuensi emocional capital pada staf pendidik UNUSA Tahun 2014

\begin{tabular}{|c|c|c|c|}
\hline No & $\begin{array}{c}\text { Emocional } \\
\text { Capital }\end{array}$ & Frek & $\%$ \\
\hline
\end{tabular}




\begin{tabular}{|l|l|l|l|}
\hline 1. & Rendah & 14 & 82,4 \\
\hline 2. & Tinggi & 3 & 17,6 \\
\hline \multicolumn{2}{|c|}{ Total } & 17 & 100 \\
\hline
\end{tabular}

Berdasarkan Tabel 10 dapat disimpulkan bahwa hampir sebagian $(82,4 \%)$ menunjukan emocional capital rendah.

Hasil crostabulation antara empowerman dan emotional capital pada staf pendidik di Fakultas Keperawatan dan Kebidanan Unusa Tahun 2014 sebagaimana disajikan pada tabel 4.11 berikut:

Tabel 11 Hasil crotabulasi antara empowerment dan emotional Capital pada staf pendidik di Fakultas Keperawatan Dan Kebidanan Unusa Tahun 2014

\begin{tabular}{|l|l|l|l|l|l|}
\hline No & \multicolumn{2}{|l|}{ Variabel penelitian } & \multicolumn{2}{|c|}{$\begin{array}{c}\text { Emotional } \\
\text { Capital }\end{array}$} & Total \\
\cline { 4 - 6 } & \multicolumn{2}{|l|}{} & Rendah & Tinggi & \\
\hline 1 & & Rendah & $100 \%$ & $0 \%$ & $\begin{array}{l}100 \\
\%\end{array}$ \\
\cline { 4 - 6 } & & & & $\begin{array}{l}100 \\
\%\end{array}$ \\
\hline
\end{tabular}

Berdasarkan Tabel 11 dapat disimpulkan bahwa empowerment dan emotional capital pada staf pendidik Fakultas Keperawatn dan Kebidanan seluruhnya (100\%) menunjukan rendah.

Hasil analisi korelasi melalui uji rank Spearman didapatkan hasil sebagaimana ditampilkan pada tabel berikut:

Tabel 12 Hasil analisis uji empowerment dan emotional capital pada staf pendidik di Fakultas keperawatan dan Kebidanan Tahun 2014

\begin{tabular}{|l|l|c|l|}
\hline No & \multicolumn{1}{|c|}{ Variabel } & Sig & \multicolumn{1}{c|}{ Ket } \\
\cline { 1 - 2 } 0 & Empowerment & 0,005 & $\begin{array}{l}\text { Terdapat } \\
\text { hubungan } \\
\text { significant }\end{array}$ \\
\cline { 1 - 2 } 2. & $\begin{array}{l}\text { Emotional } \\
\text { capital }\end{array}$ & & difal \\
\hline
\end{tabular}

Pada Tabel 4.12 dapat disimpulkan bahwa analisis rank spearman didapatkan tingkat signifikansi $\mathrm{p}=0,005<\alpha=0,05$ yang berarti Ho ditolak artinya terdapat hubungan antara empowerment dengan Emotional capital.

\section{Pembahasan}

Pada Tabel 7 dapat disimpulkan bahwa analisis rank spearman didapatkan tingkat signifikansi $\mathrm{p}=0,005<\alpha=0,05$ yang berarti Ho ditolak artinya terdapat hubungan antara empowerment dengan Emotional capital. Ha ini merujuk pada pendapat (Ancok,2002) yang menyatakan bahwa Orang yang memiliki modal emosional yang tinggi memiliki sikap positif di dalam menjalani kehidupan. Dia memiliki pikiran positif (positive thinking) dalam menilai sebuah fenomena kehidupan betapapun buruknya fenomena tersebut di mata orang lain. Ketika menghadapi perbedaan pendapat, orang yang memiliki modal emosional yang baik akan menyikapinya dengan positif, sehingga diperoleh manfaat yang besar bagi pengembangan diri, atau pengembangan sebuah konsep. Orang yang hatinya terbuka dan bersikap positif dan terbuka serta menghindari pernilaian negatif atas sebuah pemikiran orang lain akan memperoleh manfaat dari perbedaan pendapat.

Keterikatan antara empowerment dengan emotinal capital sebagaimana yang ditampilkan pada hasil penelitian ini dinyatakan bahwa emotional capital merupakan hal yang krusial yang lebih bersifat variabel, termasuk didalamnya social capital, cultural capital, human capital yang lebih komplementary (Coleman, 1988).

Emotional capital sangat mempengaruhi perkembangan empowerment seseorang sebab merujuk pada human capital (Gendron, 2004) menyatakan bahwa emotional capital merupakan hasil sebuah proses pembelajaran sehingga mampu mengubah hubungan sosial yang dapat mengembangkan sebuah kekuataan seseorang untuk lebih bisa beradaptasi dalam mengembangkan kemampuan diri.

Hubungan antara emotional capital dengan empowerment merupakan satu- 
satuan yang tidak bisa dipisahkan, (Lashley, 1999) menyatakan bahwa pada kondisi tertentu aspek emotional capital merupakan empowerment bagi seseorang secara signifikan berperan dan memberikan impak pada nilai emosi dan perasaan. Emotional capital merupakan salah satu kekuatan internal seseorang untuk mempertahakan personnal value yang mampu memberikan arti bagi pengembangan karier seseorang (Kelly, 1990). Empowerment secara umum juga sangat mempengaruhi kekeuatan perasaan seseorang untuk selalu berperilaku sesuai dengan komitmen, inisiatif, kualitas diri, dan kemauan untuk saling berbagi (Lashley., 2001).

Partisipasi para staf pendidik di

Fakultas Keperawatan dan kebidanan sebagaimana ditampilkan pada Tabel 5.7 menunjukan bahwa sebagian besar $(58,8 \%)$ sedang. Hal tersebut merujuk pada pendapat Ancok (2005) yang menyatakan bahwa partisipasi merupakan keikutsertaan seseorang dalam kegiatan kelompok sosial untuk mengambil bagian dari kegiatan masyarakat diluar pekerjaan atau profesinya sendiri. Keikutsertaan tersebut, dilakukan sebagai akibat dari terjadinya interaksi sosial antara individu yang bersangkutan dengan anggota masyarakat yang lain.

Karakteristik dari proses partisipasi ini adalah semakinmantapnya jaringan sosial (social network) yang baru membentuk suatu jaringan sosial bagi terwujudnya suatu kegiatan untuk mencapai suatu tujuan tertentu yang diinginkan. Karena itu partisipasi sebagai proses akan menciptakan jaringan sosial baru yang berusaha untuk melaksanakan tahapan kegiatan demi tercapainya keinginan masyarakat atau struktur sosial yang bersangkutan.

Dukungan sosial (social support) sebagaimana yang disajikan pada Tabel 5.8 dapat disimpulkan bahwa sebagian kecil $(29,3)$ tinggi. Hal ini merujuk pada pendapat Ancok (2005) menyatakan bahwa Dukungan sosial merupakan dukungan sumber daya yang disediakan lewat interaksi orang lain. Bentuk dukungan sosial berupa dukungan informasi, dan dukungan harga diri yang disebabkan oleh adanya interaksi kelompok sosial. Berangkat dari adanya interaksi dengan orang lain maka akan memunculkan sebuah ide yang dapat mencerahkan kemamuan orang lain untuk melakukan sebuah interaksi yang dapat menunjang pengembangan karier sebagai seorang dosen terutama dalam kemampuan dalam melakukan ide baru terkait dengan penelitian yang sesuai dengan current issue.

Persepsi terhadap empowerment sebagaimana ditampilkan pada Tabel 5.9 menunjukan bahwa sebagian besar $(76,5)$ lemah. Hal ini merujuk pada pendapat Ancok (2005) yang menyatakan bahwa Persepsi terhadap empowerment merupakan salah satu pandangan seseorang terhadap upaya pemberdayaan yang diberikan oleh organisasi. Dalam pengertian yang diberikan terhadap pemberdayaan, jelas dinyatakan bahwa persepsi terhadap empowerment merupakan pandangan seseorang terhadap proses pemberian dan atau optimasi daya ( yang dimiliki dan atau dapat dimanfaatkan oleh masyarakat), baik daya dalam pengertian kemampuan dan keberanian maupun daya dalam arti kekauasaan atau posisi tawar.

Self awarness pada staf pendidik di Fakultas Keperawatan dan Kebidanan menunjukan hasil sebagian besar $(58,8 \%)$ sedang (Tabel 5.4). Hal tersebut dapat disimpulkan bahwa kesadaran seseorang untuk mengembangkan kekampuan diri dan kemampuan organisasi dapat dikembangkan searah dengan tujuan organisasi (Chambers (1995). Kemampuan seseorang dalam mengembangkan self awarness merupakan salah satu kondisi seseorang yang mampu memahami emosi diri sendiri secaa tepat dan akurat dalam berbagai situasi konsisten Bradberry \& 
Greaves (2005) dalam Ancok (2005). Kemampuan dosen pada Fakultas Keperawatan dan Kebidanan mampu menguasai self awarness yakni reaksi emosi disaat menghadapi suatu peristiwa yang memancing emosi, sehingga seseorang dapat memahami respon emosi dirinya sendiri dari segi positif maupun segi negatif.

Hasil penelitian sebagaimana disajikan pada Tabel 5 menunjukan bahwa social awarness pada staf pendidik di Fakultas Keperawatan dan Kebidanan sebagian besar $(52,9 \%)$ tinggi, hal ini merujuk pada pendapat Acok (2005) yang menyatakan bahwa kemampuan untuk memahami emosi orang lain dari tindakannya yang tampak. Ini adalah kemampuan berempati, memahami dan merasakan perasaan orang lain secara akurat. Dengan adanya pemahaman ini individu sudah memiliki kesiapan untuk menanggapi situasi emosi orang lain secara positif.

Emotional capital merupakan hasil kompilasi dari self awarness dan social awarness sebagaimana disajikan pada Tabel 6 dapat disimpulkan bahwa hampir sebagian $(82,4 \%)$ menunjukan emotional capital rendah. Hal ini merujuk pada pendapatnya Ancok (2005) yang menyatakan bahwa kemampuan emotional capital menggambarkan kemampuan manusia untuk mengenal dan mengelola emosi diri sendiri, serta memahami emosi orang lain agar dia dapat mengambil tindakan yang sesuai dalam berinteraksi dengan orang lain.

\section{SIMPULAN}

hampir sebagian $(82,4 \%)$ menunjukan emotional capital rendah. Hal ini merujuk pada pendapatnya Ancok (2005) yang menyatakan bahwa kemampuan emotional capital menggambarkan kemampuan manusia untuk mengenal dan mengelola emosi diri sendiri, serta memahami emosi orang lain agar dia dapat mengambil tindakan yang sesuai dalam berinteraksi dengan orang lain.

\section{DAFTAR PUSTAKA}

Ancok, D. (1998). Membangun Kompetensi Manusia dalam Millenium Ketiga . Psikologika, No. 6, 5-17.

Ancok, D. (2002). Outbond Management Training. Aplikasi Ilmu Perilaku dalam Pengembangan Sumber Daya Manusia. Jogyakarrta: UII Press.

Ancok, D. (1997). Revitalisasi Sumber Daya Manusia dalam Era Perubahan. Gadjah Mada University Business Review, No. 8, 104-117.

Chambers, R. (1995). Poverty and Livelihoods: People: From Impoverisment to Empowerment. New York: New York University Press.

Cohen, D. \&. (2001). In Good Company. Boston: Harvard Business School Press.

Coleman. (1988). Social Capital in the creation of Human Capital. American Journal of Sociology , Vol.94 p. 95120.

Covey, S. (1990). Seven Habits of Highly Effective People. New York: Fireside Book.

Cunningham, I. (2002). Developing Human and Social Capital in Organizations. Industrial and Commercial Training, Vol.34, No. 4. 89-94.

Dahama, O. a. (1980). Education and Communication for Development. New Delhi: Oxford \& IBH Publishing CO.

Fear, F. a. (1985). Introduction: Rural Sociology, Community and Community Development. Canberra: AUIDP.

Friedman, J. (1992). Empowerment: The Politic of Alternative Development. Cambridge: Blackwell.

Gendron. (2004). Whhy Emotional Capital Matters in Uducation and in Labour. less Cahiers de la Maison des Sciences Economiques, Vol.35 P. 1-35. 
Goleman, D. (1996). Emotional Intelligence. New York: Bantam Books.

Lashley. (1999). Employee Service Excellence: A Framework For Analysis. Personannel Review, Vol. 28. P. 91-169.

Lippit, R. W. (1958). The dynamics of Planned Change. New York: Harcourt, Brace and World.

Mc Clelland, D. (1981). The Achieving Society. Bombay: Valkins, Ltd.

Parsons, T. (1951). The Social System. New York: The fee Press.

Rappartort, J. (1984). Studies Empowerment: Introduction to theIssue. USA: Prevention In Human Issue.

Ross, J. (1998). Intelectual Capital: Navigating the New Business Landscape. New York: MacMillan.

Sumodiningrat, G. (1997. ). Pembangunan Daerah dan Pemberdayaan Masyarakat. Jakarta: Bina Rena Pariwara.

Totok, M. (2010). Konsep-konsep Pemberdayaan Masyarakat Surakarta: UNS Press.

UNDP. (1985). General Guidelines For Capacity Assessment And Development. New York : UNDP. 